\title{
Review: some non-antibiotic treatments are effective for relieving acute sore throat
}

Thomas M, Del Mar C, Glasziou P. How effective are treatments other than antibiotics for acute sore throat? Br J Gen Pract 2000 Oct;50:817-20.

\section{QUESTION: In patients with acute sore throat, are non-antibiotic treatments effective?}

Data sources

Studies were identified by searching Medline (from 1966) and the Cochrane Controlled Trials Registry.

\section{Study selection}

Studies in any language were selected if they were controlled trials of any non-antibiotic intervention in a clinical setting. Exclusion criteria were excessive dropouts, no treatment, and unclear randomisation and blinding.

\section{Data extraction}

Data were extracted on type of treatment, definition of illness, patient characteristics, setting, blinding, and estimate of treatment effect. Outcome measures were patient centred sore throat symptoms.

Source of funding: no external funding.

For correspondence: Professor C Del Mar, Centre for General Practice, Graduate

School of Medicine,

University of

Queensland, Herston,

Oueensland 4006,

Australia. Fax +617

3365-5442.

A modified version of this abstract appears in Evidence-Based

Nursing.

\section{Main results}

22 randomised, blinded, controlled trials met the selection criteria. 7 studies involved children only, and 10 involved adults only. 10 studies measured short term outcomes $(<24 \mathrm{~h})$. The table shows the results.

\section{Conclusions}

In patients with acute sore throat, ibuprofen, steroids, non-steroidal anti-inflammatory drugs (NSAIDs), and paracetamol (acetaminophen) reduce sore throat in the short term $(<24 \mathrm{~h})$. Longer term effective treatments include paracetamol, NSAIDs, supercolonisation with benign bacteria, better doctor-patient communication, and vaccination against influenza and pneumococcus.

\section{COMMENTARY}

Sore throat is one of the most common conditions managed in primary care. Irrespective of the cause and whether antibiotics can be targeted to prevent complications, ${ }^{12}$ patients require help with symptoms. The review by Thomas $e t a l$ is important in bringing together a diverse range of evidence for non-antibiotic management, particularly given current concerns about resistance and the marginal effectiveness of antibiotics for the symptoms of sore throat in most patients.

These data suggest that paracetamol, aspirin, and other NSAIDs are effective, although there is no evidence that NSAIDs-with their greater side effects-are more effective than paracetamol alone. ${ }^{3}$ Vaccination and $\alpha$ streptococcal spray may also help, although the practicalities and cost effectiveness of such interventions are unclear. Some care is also required in interpreting the data: the estimates of treatment effect are relative and refer to diverse outcomes (pain severity, symptom resolution, and recurrence), and most studies were not done in typical primary care settings.

Clearly, more evidence is needed in primary care settings about the safety and effectiveness of non-antibiotic treatments. Nevertheless, these data should give doctors confidence that, on the basis of current evidence, non-antibiotic treatments are probably at least as effective as if not more effective than antibiotic treatment for the symptoms of sore throat.

Paul Little, MBBS University of Southampton Southampton, UK

1 Zwart S, Sachs AP, Ruijs GJ, et al. BMJ 2000;320:150-4.

2 Del Mar CB, Glasziou PP, Spinks AB. Cochrane Database Syst Rev 2000;(4):CD000023.

3 Bertin L, Pons G, d'Athis P, et al.J Pediatr 1991;119:811-4.

Non-antibiotic treatment $v$ placebo for acute sore throat*

\begin{tabular}{|c|c|c|c|c|}
\hline Treatment & $\begin{array}{l}\text { Number of trials } \\
\text { (number of patients) }\end{array}$ & Patient type & Follow up & $\begin{array}{l}\text { Relative treatment } \\
\text { effect† }\end{array}$ \\
\hline \multirow[t]{3}{*}{ Ibuprofen } & $3(118)$ & Adults & 2 to 6 hours & $32 \%$ to $80 \%$ \\
\hline & $1(78)$ & Children & 2 hours & $25 \%$ \\
\hline & $1(153)$ & Children & 2 days & $56 \%$ \\
\hline \multirow[t]{3}{*}{ Other NSAIDs } & $2(276)$ & Adults & 1 hour & $55 \%$ to $75 \%$ \\
\hline & $2(290)$ & Adults & 2 to 5 days & $17 \%$ to $81 \%$ \\
\hline & $2(207)$ & Children & 2 to 5 days & $14 \%$ to $93 \%$ \\
\hline \multirow[t]{3}{*}{ Paracetamol } & $1(81)$ & Adults & 3 and 6 hours & $50 \%$ and $20 \%$ \\
\hline & $1(77)$ & Children & 2 hours & $31 \%$ \\
\hline & $1(154)$ & Children & 2 days & $34 \%$ \\
\hline Corticosteroid plus AB & $1(51)$ & Age 12 to 65 years & 24 hours & $38 \%$ \\
\hline Aspirin containing gum & $1(20)$ & Adult men & $\leqslant 24$ hours & $50 \%$ \\
\hline Influenza vaccine & $1(849)$ & Adults & $>24$ hours & $25 \%$ \\
\hline Pneumococcal vaccine & $1(405)$ & Children & 2 years & $18 \%$ \\
\hline Supercolonisation with $\alpha$-streptococcal bacteria & $2(166)$ & Age 3 to 59 years & $\leqslant 3$ months & $42 \%$ to $90 \%$ \\
\hline Greater attention to patients plus $A B$ & $1(100)$ & Age $>16$ years & 2 days & $40 \%$ \\
\hline Benzydamine $0.15 \%$ oral rinse & $1(51)$ & Age 17 to 74 years & 3 days & $42 \%$ \\
\hline
\end{tabular}

${ }^{*} \mathrm{AB}=$ antibiotics; NSAIDs = non-steroidal anti-inflammatory drugs

†Relative decrease in symptom score in intervention group relative to placebo group. 